\title{
Multiband GaN/AlGaN UV Photodetector
}

\author{
K.P. Korona*, A. Drabińska, K. Pakula \\ AND J.M. BARANOWSKI \\ Institute of Experimental Physics, Warsaw University \\ Hoża 69, 00-681 Warsaw, Poland
}

\begin{abstract}
We present optical and electrical measurements made on GaN/AlGaN photodetector structure capable to detect three UV ranges, tuned by external voltage. The highest band at energy of about $3.85 \mathrm{eV}$ is nearly independent of bias applied to the Schottky contact. Photosensitivity of the second band at about $3.65 \mathrm{eV}$ changes strongly with the bias. Signal in this range increases about 20 times when the bias changes from $0 \mathrm{~V}$ to $-4 \mathrm{~V}$. Photosensitivity of the third band $(3.4 \mathrm{eV})$ appears for strong reverse bias $(-3 \mathrm{~V})$. Characteristics of the detector are in qualitative agreement with numerical model, however deep centers present in the AlGaN layers cause quantitative discrepancies. The concentration of defects of the order of $10^{16} \mathrm{~cm}^{-3}$ was estimated from current transients.
\end{abstract}

PACS numbers: 72.40.+w, 73.61.Ey, 73.40.Kp

\section{Introduction}

GaN/AlGaN structures exhibit many interesting properties that are related to internal electric fields caused by spontaneous and piezoelectric polarization. These polarizations result from differences in $\mathrm{Al}$ content in neighboring layers [1]. The field can be used to attract electrons which leads to formation of 2-dimensional (2D) electron gas [2] and can be used for polarization doping - an exciting technique for creating electron slabs with widely tunable density and confinement [3]. The AlGaN/GaN structure is also the most promising material for photodetection in the ultraviolet (UV) region of the spectrum, suitable to develop efficient visible blind and solar-blind sensors. Electro-tunable photodiodes are of great interest [4]. Our group reported already first achievements on GaN/AlGaN structures that were electro-tunable in two UV ranges [5]. Here we present GaN/AlGaN photodetector structure that is capable to detect three UV ranges and can be tuned by external voltage.

${ }^{*}$ corresponding author; e-mail: kkorona@fuw.edu.pl 


\section{Samples}

The investigated structures were grown by MOCVD on the sapphire substrate. Intentionally undoped, $100 \mathrm{~nm}$ GaN layer and two $40 \mathrm{~nm}$ AlGaN layers with different $\mathrm{Al}$ content of about $10 \%$ and about $20 \%$ were grown on a thick GaN:Si layer. The structure was covered with very thin GaN cap layer. Semitransparent gold Schottky contact was evaporated on the surface.

Photo-reflectance measurements showed three peaks at $3.426 \mathrm{eV}, 3.661 \mathrm{eV}$, and $3.831 \mathrm{eV}$ related to the three layers: undoped $\mathrm{GaN}, \mathrm{Al}_{0.1} \mathrm{Ga}_{0.9} \mathrm{~N}$, and $\mathrm{Al}_{0.2} \mathrm{Ga}_{0.8} \mathrm{~N}$, respectively. Additionally, line related to $2 \mathrm{D}$-gas was visible at $3.494 \mathrm{eV}$. No Franz-Keldysh oscillations (FKO) were observed, suggesting low electric field in the structure. Electro-reflectance measurements revealed significant dependence of reflectance spectra versus voltage. Clearly visible FKO from the $\mathrm{Al}_{0.2} \mathrm{Ga}_{0.8} \mathrm{~N}$ layer were observed. The $\mathrm{FKO}$ period depends on electric field [6]. The electric field calculated from these oscillations increased from 200 to $650 \mathrm{kV} / \mathrm{cm}$ when reverse bias was changed from 0 to $3 \mathrm{~V}[7]$.

\section{Results and discussion}

Photocurrent measurements showed (see Fig. 1) three spectral bands related to $\mathrm{Al}_{0.2} \mathrm{Ga}_{0.8} \mathrm{~N}, \mathrm{Al}_{0.1} \mathrm{Ga}_{0.9} \mathrm{~N}$, and $\mathrm{GaN}$ as well. The photocurrent thresholds corresponded well to the energies of respective photoreflectance peaks. The $\mathrm{Al}_{0.2} \mathrm{Ga}_{0.8} \mathrm{~N}$-related band at energy of about $3.85 \mathrm{eV}$ was practically not sensitive to bias applied to the Schottky contact. It was present under positive and negative bias as well. On the other hand, the $\mathrm{Al}_{0.1} \mathrm{Ga}_{0.9} \mathrm{~N}$-related band at $3.65 \mathrm{eV}$ changed strongly with the bias. The photosensitivity of the sample in the $3.65 \mathrm{eV}$ spectral

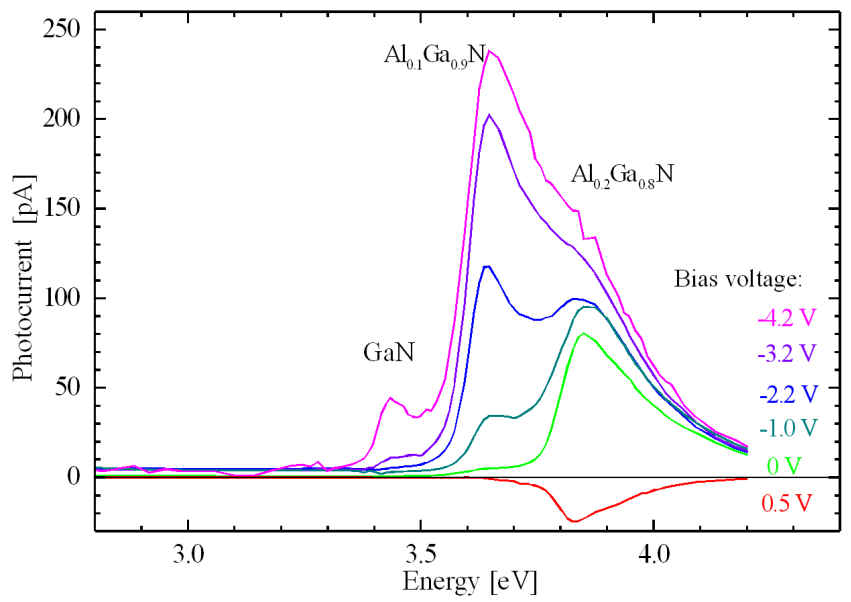

Fig. 1. Photocurrent spectra of the UV detector (without correction for the excitation spectrum). The signal in the $3.65 \mathrm{eV}$ spectral range $\left(\mathrm{Al}_{0.1} \mathrm{Ga}_{0.9} \mathrm{~N}\right)$ increases about 20 times when the bias changes from $0 \mathrm{~V}$ to $-4 \mathrm{~V}$. Photocurent in $3.42 \mathrm{eV}(\mathrm{GaN})$ region appears when reverse bias is stronger than $-3 \mathrm{~V}$. 
range increased about 20 times when the bias changes from $0 \mathrm{~V}$ to $-4 \mathrm{~V}$. Sensitivity in $3.4 \mathrm{eV}(\mathrm{GaN})$ region appears when reverse bias is stronger than $-3 \mathrm{~V}$.

Current-voltage characteristics measured at darkness and at illumination with few different photon energies correlated well with the effect observed in the photocurrent spectra. The current measured under high-energy $(3.85 \mathrm{eV})$ excitation was significantly higher than the dark current. At power of $0.1 \mu \mathrm{W}$ the photo-generated current was about $100 \mathrm{pA}$ and it was nearly voltage-independent. Photocurrent created by medium-energy $(3.65 \mathrm{eV})$ and low-energy $(3.44 \mathrm{eV})$ photons without bias was about 30 and 1000 times lower, respectively. Dark current under reverse bias up to $1.5 \mathrm{~V}$ was of the order of $0.1 \mathrm{pA}$. For stronger bias, the current increased and showed breakdown at about $4.5 \mathrm{~V}$ which was probably due to avalanche ionization of defects in AlGaN layers.

Broad range (1.2-4.2 eV) efficiency spectra (photocurrent divided by excitation intensity) of the AlGaN/GaN structure under different bias voltages were plotted in Fig. 2. It is visible that the spectra changed with bias and that the $\mathrm{Al}_{0.1} \mathrm{Ga}_{0.9} \mathrm{~N}$-related band at energy of about $3.65 \mathrm{eV}$ was the most sensitive to bias. In addition to the band-to-band transitions related to specific layers of the detector structure, there was also a photo-ionization band at energy well below the GaN band gap (threshold at $1.7 \mathrm{eV}$ ). This band was obviously related to ionization of some deep defects. The deep defect band, that had relatively low efficiency, gave in fact significant photocurrent. The current was high due to high number of low-energy photons compared to low number of UV photons. This effect can be detrimental to the UV detectors, so further investigations of its origin and means to avoid it are necessary. The current-voltage dependence of the deep-defect band suggested that it is related to the $\mathrm{Al}_{0.1} \mathrm{Ga}_{0.9} \mathrm{~N}$ and $\mathrm{Al}_{0.2} \mathrm{Ga}_{0.8} \mathrm{~N}$ layers.

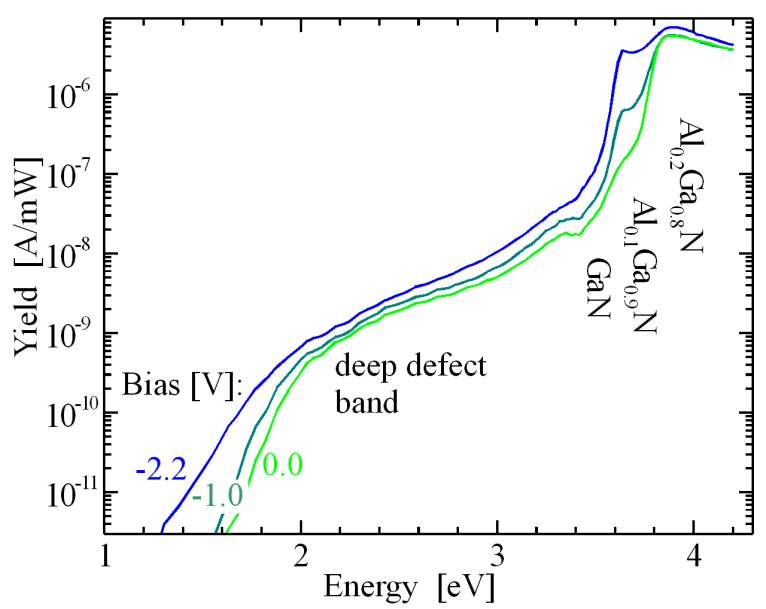

Fig. 2. Efficiency spectra (photocurrent to excitation intensity) of the AlGaN/GaN structure under different bias voltages. It is visible that the spectra change with bias. 
After switching off light, we obtained non-equilibrium distribution of carriers. Estimated time of return to equilibrium carrier distribution in darkness is $\tau_{\mathrm{E}}=$ $\varepsilon \varepsilon_{0} / e n \mu$, where $\mu$ and $n$ are mobility and concentration of the carriers. This time is of the order of $1 \mathrm{ps}$. Also reaction time of the whole device should be short, $\mathrm{RC}=2 \mu \mathrm{s}$, well below the equipment integration time $(0.5 \mathrm{~s})$. However, it was observed (see Fig. 3) that current transients after switching off illumination were longer (few seconds). The decays observed after excitation of the GaN and $\mathrm{Al}_{0.2} \mathrm{Ga}_{0.8} \mathrm{~N}$ layers were monotonic and fast, but the decay of current excited in the $\mathrm{Al}_{0.2} \mathrm{Ga}_{0.8} \mathrm{~N}$ layer showed at first a recess (at about $1 \mathrm{~s}$ ), then recovered to the dark current. The effect was observed also for $\mathrm{Al}_{0.2} \mathrm{Ga}_{0.8} \mathrm{~N}$ layer, but only at high bias. Therefore slow process can be explained only by charging of deep centers and slow reemission after switching off light. The charging could be due to trapping of photo-excited carriers or photo-ionization of the centers. Negative current suggested that there were positive charge carriers (holes) trapped in the illuminated layer. The observed emission of holes of $10 \mathrm{pC}$ gave concentration of charge traps in $\mathrm{Al}_{0.1} \mathrm{Ga}_{0.9} \mathrm{~N}$ layer $N_{\mathrm{T}}=0.8 \times 10^{16} \mathrm{~cm}^{-3}$.

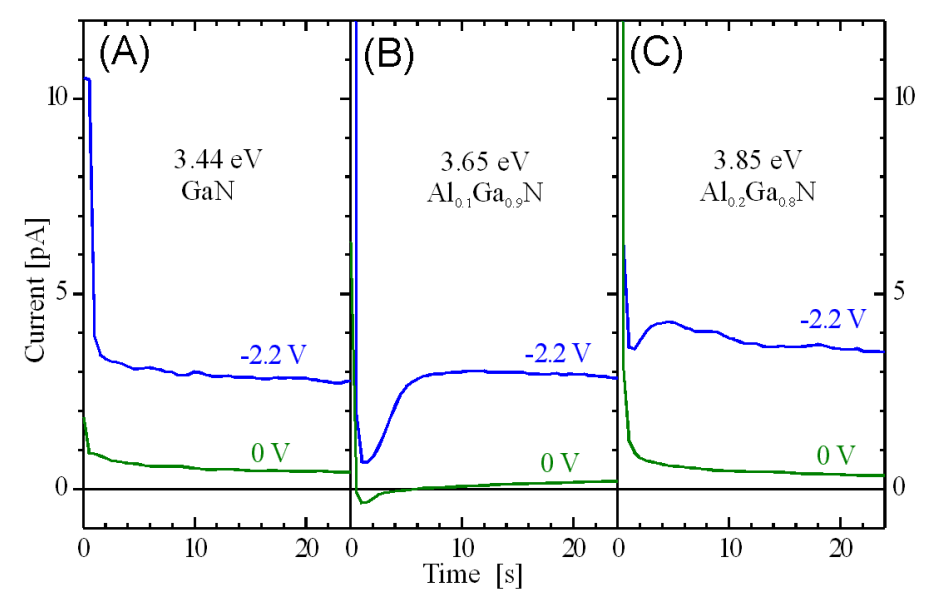

Fig. 3. Current transients after switching off illumination. The decays observed after excitation of (A) GaN and (C) $\mathrm{Al}_{0.2} \mathrm{Ga}_{0.8} \mathrm{~N}$ were monotonic and fast. The decays of current excited in (B) $\mathrm{Al}_{0.1} \mathrm{Ga}_{0.9} \mathrm{~N}$ layer showed at first a recess, then recovered to the dark current value.

In order to analyze the effects observed in this structure, we made numerical calculations of potential, electric field charge distributions and currents.

The potential and charge distributions were calculated by self-consistent procedure taking into account composition-dependent potential $\Phi_{X}$ and electric field generated by electric charges (free carriers and ionized defects) and spontaneous polarization, $P_{X}$, on the $\mathrm{GaN} / \mathrm{Al}_{0.1} \mathrm{Ga}_{0.9} \mathrm{~N}$ and $\mathrm{Al}_{0.2} \mathrm{Ga}_{0.8} \mathrm{~N} / \mathrm{Al}_{0.1} \mathrm{Ga}_{0.9} \mathrm{~N}$ interfaces. Based on electroreflectance measurements, we expected that even under 
zero bias, a strong electric field $\left(200 \mathrm{kV} / \mathrm{cm}\right.$ ) was present in the $\mathrm{Al}_{0.2} \mathrm{Ga}_{0.8} \mathrm{~N}$ (upper layer). The field could be due to the gold layer that depleted electrons during formation of the Schottky contact. The photo-reflectance measurements showed no Franz-Keldysh oscillations, suggesting lack of electric field in the structure without gold layer. However, during photo-reflectance measurements the field could be screened by electrons and holes generated by probing laser. On the other hand, previous calculation $[2,3,5]$ proved importance of piezoelectric and spontaneous polarization in AlGaN structures. Therefore, in presented calculations we had used polarization data from previous samples.

Potential $\Phi$ changes along $z$-axis

$$
\Phi(z)=\Phi_{X}-\frac{1}{\varepsilon \varepsilon_{0}} \int\left[P_{x}+e \int\left(-n+p+n_{\mathrm{D}}^{+}-n_{\mathrm{A}}^{-}\right) \mathrm{d} z\right] \mathrm{d} z,
$$

where $n, p, n_{\mathrm{D}}^{+}, n_{\mathrm{A}}^{-}$are concentrations of electrons, holes and ionized donors and acceptors, respectively. The distributions of these concentrations were calculated taking into account generation of electron-hole pairs by illumination, recombination, trapping and transport of electrons and holes. Hole distributions at different biases calculated for the planned structure under $3.65 \mathrm{eV}$ photo-excitation were plotted in Fig. 4A. It is visible that at bias from 0 to $-2 \mathrm{~V}$ a high concentration of holes was present at the undoped GaN layer. The concentration in this layer was 3 orders of magnitude higher than in the AlGaN layers. It was due to high $\mathrm{GaN} / \mathrm{AlGaN}$ band-offset taming the holes. Electric field in the $\mathrm{Al}_{0.1} \mathrm{Ga}_{0.9} \mathrm{~N}$ (middle layer) was partially screened and in the undoped GaN layer was fully screened by a high electron concentration at interfaces. At higher bias (stronger than $-2 \mathrm{~V}$ ) electric field rose up, the tunneling through the barrier became possible and electric field swept holes from the GaN layer.
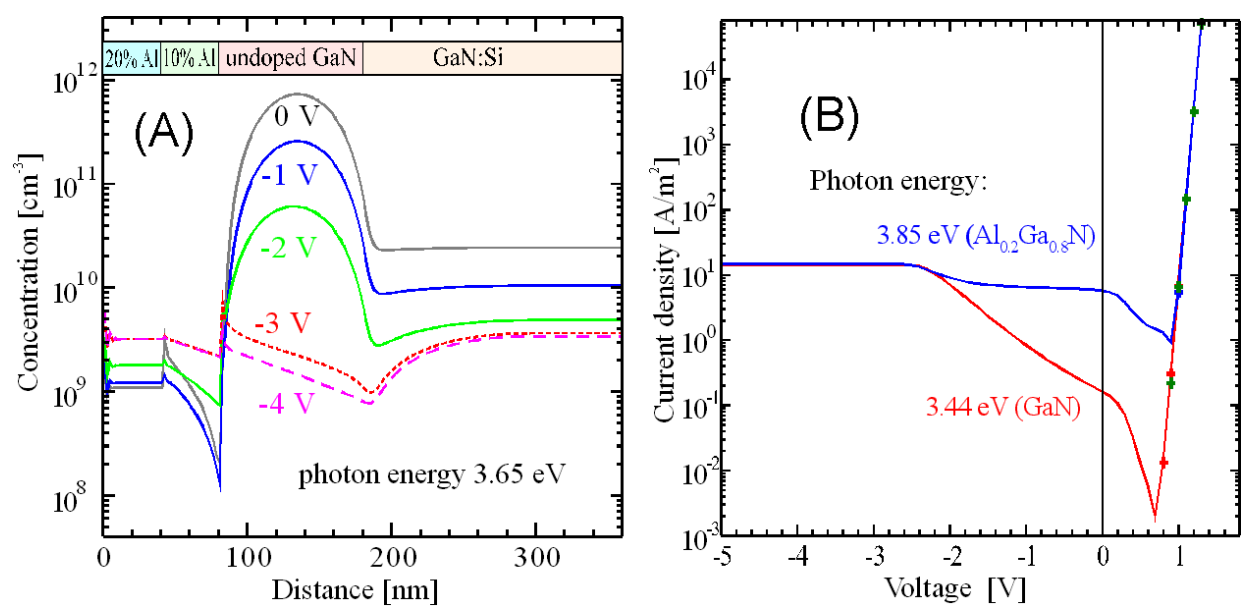

Fig. 4. (A) Hole distribution at different biases calculated for the investigated structure.

(B) Current-voltage characteristics calculated at different photon energies. 
Electron current density $j_{\mathrm{e}}(z, t)$ could be calculated for the given potential distribution using the following equation:

$$
j_{\mathrm{e}}(z, t)=e \mu_{\mathrm{e}} n \frac{\partial \Phi}{\partial z}+e D_{\mathrm{e}} \frac{\partial n}{\partial z}
$$

where $\mu_{\mathrm{e}}$ and $D_{\mathrm{e}}$ are mobility and diffusion constant of electrons. Similar equation describes hole current density $j_{\mathrm{h}}(z, t)$.

Current-voltage characteristics were calculated for the planned structure under excitation at different photon energies (see Fig. 4B). Photocurrent created by high-energy $(3.85 \mathrm{eV})$ photons was nearly voltage-independent, both in calculation and measurements. Calculations showed that in the planned structure, photoexcited current from the middle layer should be opened at $0 \mathrm{~V}$ (any reverse bias). Photocurrent from the lowest $(\mathrm{GaN})$ layers should be opened at reverse biases $-2 \mathrm{~V}$ or stronger. These values of switching voltages $(0 \mathrm{~V}$ and $-2 \mathrm{~V})$ were different than values observed experimentally $(-2 \mathrm{~V}$ and $-3 \mathrm{~V})$ which was most probably due to parallel transport via deep centers present in the AlGaN layers that reduced electric field. Since the fields were responsible for switching, the switching voltage increased. The calculated dark current was much lower than the observed one, which was due to parallel transport by defects in real sample.

\section{Conclusions}

It was shown that tunable, multi-range UV photodetector can be realized on GaN/AlGaN structure. The detector worked in three ranges $3.4 \mathrm{eV}, 3.65 \mathrm{eV}$ and $3.85 \mathrm{eV}$ related to its three active layers. Characteristics of the detector were in qualitative agreement with numerical calculations. However, in real samples higher dark current and stronger switching biases were observed. The switching biases were $-2 \mathrm{~V}$ and $-3 \mathrm{~V}$ for $3.85 / 3.65 \mathrm{eV}$ and $3.65 / 3.4 \mathrm{eV}$ bands, respectively.

The differences between planned and obtained parameters of the detector were most probably due to deep centers present in the AlGaN layers. The defects allowed parallel transport (probably by hopping) that increased dark current and reduced electric fields. Since the fields were responsible for switching, the switching voltage increased. The defects were also responsible for slower than expected current decays. The concentration of defects of the order of $10^{16} \mathrm{~cm}^{-3}$ was estimated from the current transients.

\section{Acknowledgments}

This work was partially supported by grant No. 3 T11B 05430 (financed by the Ministry of Science and Higher Education in years 2006-2008).

\section{References}

[1] F. Bernardini, V. Fiorentini, D. Vanderbilt, Phys. Rev. B 56, R10024 (1997).

[2] A. Drabińska, K.P. Korona, R. Bożek, J.M. Baranowski, K. Pakuła, T. Tomaszewicz, Phys. Status Solidi C 0, 329 (2003). 
[3] D. Jena, S. Heikman, J.S. Speck, A. Gossard, U.K. Mishra, A. Link, O. Ambacher, Phys. Rev. B 67, 153306 (2003).

[4] J. Hwang, M.H. Song, B. Park, S. Nishimura, T. Toyooka, J.W. Wu, Y. Takanishi, K. Ishikawa, H. Takezoe, Nature Mater. 4, 383 (2005).

[5] K.P. Korona, A. Drabińska, A. Trajnerowicz, R. Bożek, K. Pakuła, J.M. Baranowski, Acta Phys. Pol. A 103, 675 (2003).

[6] D.E. Aspnes, A.A. Studna, Phys. Rev. B 7, 4605 (1973).

[7] A. Drabińska, K.P. Korona, K. Pakuła, J.M. Baranowski, submitted to Phys. Status Solidi A. 